\title{
Online Group Counseling with Mindfulness-Based Cognitive and Solution-Focused Approach for Enhancing Students' Humility
}

\author{
Rohmatus Naini, Mulawarman Mulawarman, and Mungin Eddy Wibowo
}

\begin{abstract}
Character education is also an important thing to be developed by school counsellors. The humility is one of necessary character that based others virtue. The student's problems who have low humility tend to have difficulty accepting criticism/information from others, arrogance, sadism, selfishness, and bullying behavior. During the Covid-19 pandemic, the learning system used the internet, including counselling services. This study aims to test an effective approach in increasing the character of humility between mindfulness-based cognitive or solution-focused approach. The group counseling design used is the synchronous for the counselling process and asynchronous to complete the worksheet. This experimental study involved 24 students in each group of 8 students aged 14-17 years. This participant of research is limited. The scale used to measure humility is Elliot's theory of adaptation which is designed using a Likert-scale. There are four aspects, namely openness, self-forgetfulness, accurate self-assessment, and focus on other things with a total of 32 items. The reliability humility scale is 0.901 , and CAMM $\alpha=0.790$. These results indicate no significant difference in MBCT-SFBT in increasing humility, whereas MBCT-control \& SFBT-control have a significant difference. That is, the mindfulness group had an increase in the mean between pretest-posttest and follow-up. This study found that character enhancement can use mindfulness-based cognitive and solution-focused approach. Both of them have the characteristics of character strengths and applicable by school counsellors. This study has few subjects so that the research subjects in further research are to increase the number of studies and make online and non-online comparisons.
\end{abstract}

Index Terms-Online counselling, humility, mindfulness-based cognitive, solution-focused.

\section{INTRODUCTION}

Mindfulness research is a popular research topic in Indonesia, but it is still not widely applied in educational or non-clinical settings. According to Panteleno \& Sisti, mindfulness is the root of Buddhism and is often defined as the ability to be aware and mindful at this time (in Vernon \& Doyle) [1]. It is not only a practice, but it is interpreted as a condition, nature, process and result (Singh et al.) [2]. Wallin [3] also explains that mindfulness is also understood as a developmental process for understanding self and other people's behaviour in terms of individual thoughts, feelings

Manuscript received December 28, 2020; revised June 14, 2021. This work was supported in part by Indonesia Endowment Fund for Education.

The authors are with Universitas Negeri Semarang, Indonesia (e-mail: rohmatusnaini@students.unnes.ac.id, mulawarman@mail.unnes.ac.id, mungineddy@mail.unnes.ac.id). and desires which can affect cognitive regulation and flexibility. Mindfulness practice also develops interpersonal aspects related to relationships with interactions with other people that intrapersonal aspects such as well-being, association functions in the brain such as self-insight, morals and intuition (Davis \& Hayes) [4].

One mindfulness in intervention model is mindfulness-based cognitive therapy, abbreviated as MBCT (Segal, Teasdale \& Williams) [5] where the praxis focuses on the concepts of acceptance, letting go, patience and openness which are also related to strength. The characteristics such as self-regulation and decision making. This intervention is often used in clinical settings, so that the setting in schools is still minimal. Researchers want to test MBCT with an online group counselling design to improve students' humility. The concept of humility is in line with the concept of MBCT where individuals learn to regulate attention and elaborate on awareness of experience and acceptance (Bishop, et al.,) [6] which are related to aspects of humility Elliot [7], namely openness; open to new ideas, able to accept suggestions from others and understand their weaknesses and strengths and focus on others. Individuals who have humility will try to let go and move on, to become humble individuals.

Apart from testing MBCT for humility, a solution-focused approach was also examined in this study. A solution-focused approach defines individuals as having the ability to succeed in overcoming difficulties, but it is just that they cannot solve problems due to loss of trust, loss of direction and loss of sources of consciousness (Peterson \& Seligman) [8]. Solution-focused on the meaning of a problematic individual is a belief that unhappiness or welfare comes from him, for example, by labelling their self instead of constructing one's strength or ability as a basis for problem-solving (Mulawarman) [9]. This intervention model is more on a conversation based on the client's strength (Terni) [10]. According to Wong [11] that solution-focused therapy emphasizes the strength of character by exploring it so that new meanings emerge based on subjective experiences by clients. Because the solution-focused approach emphasizes client strengths and resilience (De Shazer in Corey) [12], so that in assuming a solution-focused approach following with the characteristics of humility. Kim et al. [13] stated that a solution-focused approach is an alternative school program providing appropriate and effective services in dealing with adolescent problems.

Humility is one of the sub-factors of personality in the HEXACO model 6, which is also part of developt character strength (Saricam et al.,) [14]. Some attributes related to 
humility include optimism, hope, respect for a positive life, personal relationships, gratitude, responsibility, empathy, humanism, kindness etc. Humility is also used as a basis for virtue to develop other good characters (Wright et al.) [15]. Individuals without humility tend to have selfish, arrogant and perfect-minded attitudes (Anderson in Rowartt et al., 2006) [16]. Humility is important to develop because it can predict academic achievement and social skills (Macdonald, Bore, \& Munro, 2008) [17]. However, specific interventions to increase humility have not been widely studied.

Through this study, he wanted to test which online group counselling had a more significant increase in humility between the mindfulness-based cognitive or solution-focused groups.

\section{METHODS}

\section{A. Design}

This study used true experimental methods design with randomized pre-test post-test control group design. Participants were divided into three groups, each measuring pre-, post-, and follow-up after two weeks after the last meeting.

\section{B. Participants}

The study was conducted in Semarang City-Central Java Indonesia, where clients are students in senior high school with an age range of 14-17 years. The number of clients, namely 24 students, was divided into three groups: eight students for the mindfulness-based cognitive group, eight students for the solution-focused group, and eight students for the control group. This participant of research is limited. The inclusion criteria for being a participant in this research were having a low humility assessment score and low mindfulness-skills based on preliminary study results and screening participants. Besides, because this research was conducted online, participants needed to have a zoom account.

\section{Procedure}

The informed consent was signing to agreement by participants. The data collection process is designed like group counselling in general, including the opening stage, the transition stage, the work stage and the closing stage, this is done in each session. The mindfulness group was modified into five counselling sessions, the solution-focused group, five counselling sessions, and four counselling sessions for the control group (one session per week). The three groups carried out humility measurements at pre-, post, and follow-up (after two weeks of giving the final treatment) except for the mindfulness group also measuring mindfulness skills. Session content for the mindfulness-based cognitive group included the first session of orientation, problem identification, practising short meditation and eating meditation, second: automatic pilot, practising body scan and sitting meditation, third: practising 3-minutes breathing, practising gratitude and forgiveness, fourth: understand the sign of stress and practice self-compassion, fifth: compile an activity plan. Besides, clients also practice independently at home for five days a week and record them in a daily mindfulness journal.

Several assignments and techniques were given to solution-focused groups including the first session identifying the problems to be solved, second: formulating specific goals, third: building solutions, fourth: facilitating understanding and awareness, fifth: evaluation and follow-up. Some of the things that the counsellor do to clients are rating scale, miracle questions, exceptions questions, coping questions, relational questions, taking a break, skeleton keys questions, and compliment. In the control group, it was carried out like Treatment As Usual (TAU).

\section{Measures}

\section{1) Humility scale}

The humility scale (Elliot) [7] has 32 items which are arranged based on four aspects of humility including, openness, self-forgetfulness, accurate self-assessment and focused on others. Alternative answer choices use a 1-4 Likert scale (Very Fit, Suitable, inappropriate and very inappropriate). Several previous researches also used this instrument such as 0.842 (Elliot) [7]; Fitriani \& Agung [18] $\alpha$ $=0.842$; Sapmaz et al. [19] $\alpha=0.63$; Saricam et al. [14]] adapt only 13 item with consistency coefficient $0.63,0.67$, $0.72 \& 0.79$ in four aspects. In this research $\alpha=0.901$.

\section{2) Child and adolescence mindfulness measurement}

Greco, Baer \& Smith's CAMM (2011) [20] are some 10 items that identify how individual implement mindfulness skills in daily activities. The answer choices also use a 1-4 Likert scale (Very Fit, Suitable, inappropriate and very inappropriate). Previous research using CAMM with $\alpha=0.80$ (Greco, Baer \& Smith) [21]; Bruin et al. [21] $\alpha=0.71$; Piqueras, et al. [22] with Spanish \& Portuguese version $\alpha=$ 0.85 and 0.76 . The results of the coefficient reliability are 0.790 .

\section{E. Data Analysis}

All data were analysed using the Statistical Package for the Social Science (SPSS) version 24.00. Before testing the hypothesis, the researcher conducted a normality test with Shapiro-Wilk due to the small number of samples., Researchers used the paired t-test to see differences within subjects and comparisons between groups using two-way repeated-measure Anova.

\section{RESULTS}

The data analysis results of the three groups by looking at the within-subject analysis results as you can see from Table I.

TABEL I: COMPARISONS OF WITHIN SUBJECTS

\begin{tabular}{ccccccc}
\hline \multirow{2}{*}{ Time } & \multicolumn{2}{c}{ MBC } & \multicolumn{2}{c}{ SF } & \multicolumn{2}{c}{$\mathrm{C}$} \\
\cline { 2 - 7 } & $\mathrm{T}$ & $p$ & $\mathrm{~T}$ & $p$ & $\mathrm{~T}$ & $P$ \\
\hline T1 VS T2 & -18.391 & 0.001 & -13.48 & 0.01 & -12.96 & 0.01 \\
\hline T2 VS T3 & -5.769 & 0.001 & -2.296 & 0.06 & -2.411 & 0.05 \\
\hline T1 VS T3 & -30.549 & 0.001 & -12.86 & 0.01 & -13.98 & 0.01 \\
\hline
\end{tabular}

Notes: MBC = Mindfulness-based cognitive; $\mathrm{SF}=$ Solution-focused; $\mathrm{C}=$ Control; T1 $=$ pre-test; $\mathrm{T} 2=$ Post-test; $\mathrm{T} 3=$ follow up.

The Mindfulness group experienced a significant and 
significant change in the humility score marked by $(p<0.05)$, the comparison of T1-T2 $(t=18,391 ; p=0.001)$, T2-T3 $(t=$ $-5,769, p=0.001)$ and T1- T3 $(t=-30.549, p=0.001)$. Whereas in the solution-focused group, changes in students' humility scores in the solution-focused group at T1-T2 $(t=$ 13.48; $p=0.01)$ and T1-T3 $(t-12.86, p=0.01)$, however, did not experience any difference. The current score at T2-T3 $(t=$ $-2.296, p=0.06$ ) was due to $\mathrm{p}>0.05$. There was a change in the humility scores that students had in the control group at T1-T2 $(t=-12.96 ; \mathrm{p}=0.01)$ and T1-T3 $(t-13.98, p=0.01)$, however, there was no difference in humility scores at T2-T3 $(t=-2.411, p=0.05)$ because $\mathrm{p}=0.05$. Based on the results of increasing pretest to follow-up, the mindfulness group had a higher mean change in humility improvement than the solution-focused and control groups. The solution-focused group also experienced an increase in humility from pretest to post-test but when viewed from the pretest-follow-up, the control group had a slightly greater mean.

To see the direction of increase in each group, here is a table of increasing humility based on time and treatment (Fig. $1)$.

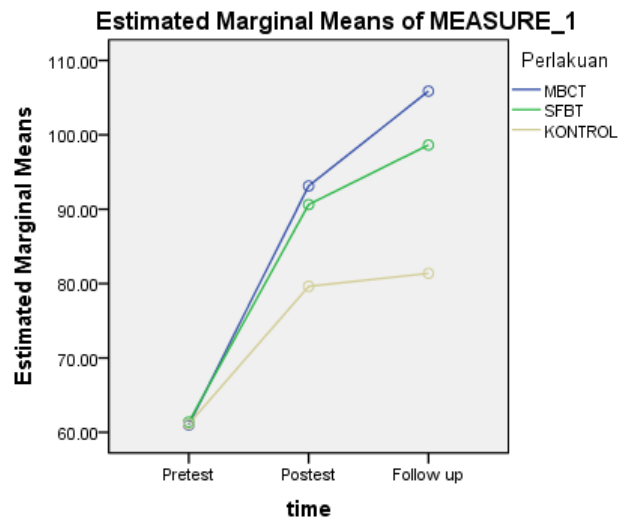

Fig. 1. The effectiveness between experimental group and control group.

It can be observed that the graphs of the MBCT, SFBT and control groups have shown a significant increase from pre-test to post-test, but the SFBT and control groups experienced modest increases (no difference) at post-test to follow-up. Meanwhile, MBCT has consistently increased, and has increased significantly in the three measurement times.

Based on data analysis for each treatment and time, the data in the explanation above were obtained, then the researcher also saw the differences between groups that were paired with a pair-wise comparisons analysis, obtained the following data.

TABLE II: MULTIPLE COMPARISONS (BETWEEN GROUPS)

\begin{tabular}{cccccc}
\hline Groups & & MD & SE & $p$ \\
\hline MBCT - SFBT & & 3.12 & 1.32 & 0.15 \\
\hline MBCT - control & \multicolumn{2}{c}{12.62} & 0.87 & 0.001 \\
\hline SFBT - control & & 9.5 & & 1.55 & 0.001 \\
\hline Humility & df & & F & $p$ & $\eta_{\mathrm{p}}{ }^{2}$ \\
\hline & $(2,14)$ & 52,57 & 0.001 & 0.73 \\
\hline
\end{tabular}

Based on the Table II above, it is known that the MBCT SFBT there is no significant difference in increased humility $(p<0.05)$ between the two groups $(\mathrm{MD}=3.12 ; \mathrm{SD}=1.32 ; p$ $=0.15)$, whereas when compared between MBCT - Control $(\mathrm{MD}=12.62 ; \mathrm{SE}=0.87 ; p=0.001)$ and SFBT - Control $(\mathrm{MD}$
$=9.5 ; \mathrm{SE}=1.55 ; p=0.001)$ there was a significant change in the mean increase in humility. Furthermore, a two-way-repeated-measure ANOVA calculation is performed in the table below. The results of the two-way-repeated Anova test showed that there was a significant interaction between students' humility in the group as evidenced by $(F(2,14)=52,764, p=0.001,1 \mathrm{p} 2=$ 0.73 . The interpretation of the $\Pi \mathrm{p} 2$ score showed a large interaction effect due to $\Pi \mathrm{p} 2>0.14$. It can be interpreted that the statistical results show a large interaction effect based on time and treatment. Mindfulness and solution-focused interventions have an effect on increasing students' humility.

\section{DISCUSSION}

These three interventions were carried out through online group counselling. From the three interventions above, it is known that online counselling with a mindfulness-based cognitive and solution-focused approach can increase students' humility. A mindfulness-based cognitive approach was more effective than solution-focused and control groups. Compared with the mean humility scores obtained by students at post-test and follow-up, mindfulness-based cognitive has a higher mean change than the control group (almost twice the solution-focused score).

Research subjects in all three groups showed increased humility, including the control group. Essential findings for changes in humility in the mindfulness and solution-focused groups were accompanied by large effect sizes, but when compared between the two groups a large change was found in the mindfulness groups, significant improvement in humility in the mindfulness and solution-focused groups after the post-test and the effect of major changes occurred after the follow-up measurements. For the control groups, There was little effect change (one-third of the change in the solution-focused group) at post-test and, tiny change sizes were found post-follow-up. Explore the effects of the mindfulness and solution-focused groups on outcomes depending on pre-treatment trends. The mindfulness group had lower humility than the solution-focused group; this indicates that the humility score increased significantly. However, this interpretation needs to be re-examined, given the relatively small number of research subjects.

Jayawardene et al., [23] in their research stated that online mindfulness preventive interventions in non-clinical settings, especially the academic environment, workplace, or community, can be substantially effective in reducing personal stress, especially middle-aged people and increasing attention. Given the increase in digital access (Zickuhr \& Smith [24], especially among young and middle-aged people in the academic and workplace environment online mindfulness interventions can be used as a more convenient and economical intervention strategy cost rather than face to face. Dense individual busyness makes it difficult to reach it to be used digitally by a larger population (Barak et al.,) [25].

The success element of online intervention is that the counsellor can use psychoeducation, empathy, self-disclosure, self-efficacy formation, alliance strengthening, flexibility in assignment deadlines, task reinforcement and task prompting, all of which are related to 
the results of the intervention indicated by a decrease in symptoms experienced by the client (Paxling et al. [26]. Parsons et al., [27] explain that home practice is important because it can affect therapeutic changes. Weck et al., [28] apart from the client itself who made the success of MBCT, the competence of a therapist or counsellor in providing a protocol for practising mindfulness and conducting a homework review is also a relevant factor. Sipe \& Eisendrath [29] stated that mindfulness-based cognitive therapy is characterized by distinguishing dysfunctional and negative thoughts from healthy thinking, testing and challenging dysfunctional beliefs and finding new interpretations, and reinforcing more adaptive responses.

The difference between a counsellor/therapist who performs online-based interventions is that they do not do "teaching" or detailed directions such as face-to-face interventions. In particular, clients have the primary responsibility in obtaining theoretical knowledge from reading, watching material on the internet or other sources which are also managed in weekly assignments/weekly modules (Maas et al., 2020) [30].

Andersson [31] also explains that the role of therapists in online intervention has shifted to support such as providing instructions, providing feedback related to worksheets done at home or answering questions, because the counsellor/therapist is not the key to client success. Also, online sessions are more on communication involving written messages or facial expressions/intonations which can also be implied, for example using symbols, or the like they are flexible in execution which also involves contact with clients starting from their daily context.

A meta-analysis (Parsons et al.,) [27] across 28 studies confirmed that there was a significant relationship between participants in-home practice in MBCT and outcome of the intervention. So, with increased exercise, better results can be achieved. Furthermore, the intensity of the eMBCT program can play a role in achieving goals. Research that has been conducted by (Sánchez-Ortiz et al.,) [32] shows that online cognitive behaviour therapy can effectively support behaviour change internet-based, so individuals are more independent in obtaining information and are responsible for following online modules, so that the role of the therapist becomes natural supporters.

Parsons et al., [27] results of research conducted with MBCT and MBSR that about $60 \%$ of research subjects complete daily tasks at home to which individuals have substantially committed time to practice consistently, although less than suggested in standard format interventions (Maas et al. al.,) [30]. Segal et al., [5] the results of the intervention show positive evidence in treatment outcomes even though the significance is small. The success factor of the intervention is also influenced by compliance and self-awareness. Helbig \& Fehm [33] added that the motivation factor to change also affects the completion of homework. Sedlmeier et al., [34] in their study showed that the impact of mindfulness-based meditation generally gave a positive impact on psychological variables and a substantial impact on negative emotions rather than cognitive.

So it can be concluded that online MBCT is higher due to assignments that need to be completed by clients and to practice independently for a certain period with informal mindfulness practices that are applied in daily activities. The client in this study did daily practice five times a week and every day about 10-15 minutes (50-75 minutes a week / 300 minutes / 50 hours for seven weeks). The difference with the solution-focused group and the control group was the independent home exercise. The number of sessions in this study for the mindfulness group was conducted for five sessions, the solution-focused group was given 5 sessions and the control group only four sessions. In the practice of mindfulness, success is seen from full attention and the intention to practice and also the consistency of applying mindfulness affects individual attitudes in achieving the goal of alleviating the problems experienced.

Comparative research conducted by Frostadottir \& Dorjee [35] examining the effectiveness of mindfulness-based cognitive therapy and compassion focused therapy shows that both are effectively increase mindfulness and self-compassion, reducing anxiety, depression, rumination and stress. However, the MBCT group had the advantage that follow-up measures significantly reduced anxiety and experienced significant improvement in mindfulness in the post-test.

In empirical studies, mindfulness and humility are related. However, similar research has not been found, but its relevance to previous research, namely mindfulness and character strengths, and humility are part of these character strengths. In addition to contributing to individual welfare, character strengths also improve the welfare of others in the individual's social environment (Niemiec,) [36]. Linley et al., [37] stated that the strength of character could increase students' academic goals. The operational definition of mindfulness prepared by Bishop et al., [6] is that mindfulness involves self-regulation and attention (self-regulation \& attention) as well as an attitude of curiosity, openness and acceptance. In this context, by operational definition, the elements in mindfulness are also contained in humility indicators including openness, self-forgetfulness, accurate self-assessment and focused on others.

Niemiec et al., [38] stated that mindfulness and character strength are elements possessed by humans as the potential for growth and development that can be integrated to create a positive, virtue impact. Through mindfulness, it can help individuals in expressing their character's strengths in a balanced, sensitive, and supportive way to overcome obstacles by paying attention ultimately. Practising mindfulness can also be implemented in real-life situations, so that life is mindful, for example in, this study, group members do mindfulness in situations of making decisions, learning and eating activities and activities that involve other people.

The counselor can optimize technology and information because it has a great opportunity in the success of the process of providing group counseling services, because clients can feel freedom in expressing and high self-disclosure in telling problems (Anni, Sunawan \& Haryono) [39] and one of the benefits is that it can improve client performance and well-being (Hernawati, Sugiarto, Purwanto, Awalya) [40]. 


\section{Conclusions}

The mindfulness-based cognitive approach of online group counselling contributes to the process of increasing students' low humility. This conclusion is following with final analysis results that mindfulness-based cognitive has increased from pre-test to post-test is quite large and has increased humility back from post-test to follow-up. Whereas for online group counselling, a solution-focused approach can also improve students' humility, as evidenced by the measurement after being given the intervention, namely pre-test to post-test, it appears that a significant increase is seen. However, there was no significant improvement after the post-test humility measurements were returned to follow-up.

Additional analysis proves that when compared between mindfulness-based cognitive and solution-focused, there is no difference, meaning that having similarities can increase students' humility effectively. If a comparison is made between the mindfulness group and the control group, the mindfulness group has a higher increase than the control group. It was also found that the solution-focused group experienced more humility improvements and, there was a difference in humility scores between the solution-focused group and the control group.

\section{LIMITATIONS AND RECOMMENDATION}

This study also has limitations including the first: because data collection was carried out during the Covid-19 pandemic, students tended to have more learning workloads than face-to-face learning processes, so researchers did not measure students' stress or depression prevalence. Second, researchers do not take measurements outside the dependent variable, which is another factor of humility. Third, in the data collection process the researcher cannot fully control the activity, for example observing body movements in detail (because what can be observed is only eye contact, gesture although not in full, intonation, verbal and non-verbal expressions). Fourth, the technical problems found were network stability or interference with a laptop or mobile devices.

Recommendations for research development include the need to know the psychological conditions of students such as stress, depression, anxiety and so on to anticipate the success of providing service with solution-focused and mindfulness. In addition, it is necessary to conduct development research related to the media used in the innovative online group counselling process. Further researchers can conduct comparative research by comparing the effectiveness of mindfulness-based cognitive interventions and solution-focused between online and face-to-face. Other idea is find some factors that influence increased humility, it is necessary to have a moderating or mediating variable. For further research, it is necessary to use a larger and more varied number of subjects from a multicultural setting.

\section{CONFLICT OF INTEREST}

The authors declare no conflict of interest.

\section{AUTHOR CONTRIBUTIONS}

$\mathrm{RN}$ performed the measurement and collecting data. MM and MEW were involved planning and supervises the work. RN, MM, MEW contributed to the design and implementation of the research, to the analysis of the results and to the writing of manuscript.

\section{REFERENCES}

[1] V. Ann and D. K. Anne, Cognitive Behavior Therapy: A Guidebookfor Practicioners, American Counseling Association, 2017.

[2] N. N. Singh et al., "Mindfulness approaches in cognitive behavior therapy," Behavioural and Cognitive Psychotherapy, 2008, vol. 36, no. 6, pp. 659-666.

[3] D. J. Wallin, Attachment in Psychotherapy, Guildford Press, 2007

[4] D. E. Davis et al., "Relational humility: Conceptualizing and measuring humility as a personality judgment," Journal of Personality Assessment, 2011, vol. 93, pp. 225-234

[5] Z. V. Segal, J. D. Teasdale, and J. M. G. Williams, Midfulnes Based Cognitive Therapy, New York: The Guilford Press, 2013.

[6] S. R. Bishop et al., "Mindfulness: A proposed operational definition," Clinical Psychology: Science and Practice, 2006, vol. 11, no. 3, pp. 230-241.

[7] E. J. Charles, "Humility: Development and analysis of a scale," $\mathrm{PhD}$ dissertation, University of Tennessee, 2010.

[8] C. Peterson and M. E. P. Seligman, Character Strengths and Virtues: A Handbook and Classification, American Psychological Association, Oxford University Press, 2004.

[9] Mulawarman, Solution-Focused Brief Counseling: Konseling Singkat Berfokus Solusi; Konsep, Riset, dan Prosedur, Jakarta: Prenada Media Group, 2019.

[10] T. Paolo, "Solution-focus: Bringing positive psychology into the conversation," International Journal of Solution-Focused Practices, 2015, vol. 3, no. 1, pp. 8-16.

[11] W.Y Joel, "The future of positive therapy," Psychotherapy: Theory, Research, Practice, Training, vol. 43, no. 2, 2006.

[12] C. Gerald, Theory and Practice of Ccounseling and Psychotherapy $\left(10^{\text {th }}\right.$ ed), USA: Cengage Learning, 2016.

[13] K. Johnny et al., "Is solution-focused brief therapy evidence-based? An update 10 years later," Families in Society: The Journal of Contemporary Social Services, 2019, vol. 1, no. 12.

[14] H. Sariçam et al., "The Turkish version of the rendah hati scale: The study of validity and reliability," Kalem Eğitim ve Insan Bilimleri Dergisi, 2012, vol. 2, no. 2, pp. 165-188.

[15] J. C. Wright et al., "The psychological significance of humility," The Journal of Positive Psychology, 2017, vol. 12, no. 1, pp. 3-12.

[16] W. C. Rowatt et al., "Development and initial validation of an implicit measure of humility relative to arrogance," The Journal of Positive Psychology, 2006, vol. 1, no. 4, pp. 198-211.

[17] C. Macdonald, M. Bore, and D. Munro, "Values in action scale and the Big 5: An empirical indication of structure," Journal of Research in Personality, 2008. vol. 42, no. 4, pp. 787-799.

[18] F. Yulia and A. I. Muhammad, "Religiusitas Islami dan Kerendahan Hati dengan Pemaafan pada Mahasiswa," Jurnal Psikologi. 2018, vol. 14 , no. 2 .

[19] S. Fatma et al., "Gratitude, forgiveness and humility as predictors of subjective well-being among university students," International Online Journal of Education, 2016, vol. 8, no. 1, pp. 38-47.

[20] L. A. Greco, R. A. Baer, and G. T. Smith, "Assessing mindfulness in children and adolescents: Development and validation of the child and adolescent mindfulness measure (CAMM)," Psychological Assessment, 2011, vol. 23, no. 3, pp. 606-614.

[21] I. B. Esther et al., "The meaning of mindfulness in children and adolescents: Further validation of the child and adolescent mindfulness measure (CAMM) in two independent samples from the Netherlands," Mindfulness, 2013, vol. 5, no. 4.

[22] A. P. Jose et al., "Strengths against psychopathology in adolescents: Ratifying the robust buffer role of trait emotional intelligence," International Journal of Enviromental Research and Public Health, 2020

[23] W. P. Jayawardene, D. K. Lohrmann, R. G. Erbe, and M. R. Torabi, "Effects of preventive online mindfulness interventions on stress and mindfulness: A meta-analysis of randomized controlled trials," Preventive Medicine Reports, 2017, vol. 5, pp. 150-159.

[24] K. Zickuhr and A. Smith, While Increased Internet Adoption and the Rise of Mobile Connectivity Have Reduced Many Gaps in Technology 
Access over the Past Decade, for Some Groups Digital Disparities still Remain, vol. 41, 2012.

[25] A. Barak, B. Klein, and J. G. Proudfoot, "Defining internet-supported therapeutic interventions," Annals of Behavioral Medicine, 2009, vol. 38 , no, 1, pp. 4-17.

[26] G. Andersson et al., "Therapist behaviours in internet-delivered cognitive behaviour therapy: Analyses of e-mail correspondence in the treatment of generalized anxiety disorder," Behavioural and Cognitive Psychotherapy, 2013, vol. 41, no. 3, pp. 280-289.

[27] C. E. Parsons, C. Crane, L. J. Parsons, L. O. Fjorback, and W. Kuyken, "Home practice in mindfulness-based cognitive therapy and mindfulness-based stress reduction: A systematic review and meta-analysis of participants' mindfulness practice and its association with outcomes," Behaviour Research and Therapy, 2017, vol. 95, pp. $29-41$.

[28] F. Weck et al., "The relationship between therapist competence and homework compliance in maintenance cognitive therapy for recurren depression: Secondary analysis of a randomized trial," Behavior Therapy, 2013, vol. 44, no. 1, pp. 162-172.

[29] W. E. B. Sipe and S. J. Eisendrath, "Mindfulness-based cognitive therapy: Theory and practice," The Canadian Journal of Psychiatry, 2012, vol. 57, no. 2, pp. 63-69.

[30] A. Maas et al., "Therapist behaviours in a web-based mindfulness-based cognitive therapy (eMBCT) for chronic cancer-related fatigue - Analyses of e-mail correspondence," Internet Interventions, 2020, vol. 22, p. 100355.

[31] A. Gerhard, "Internet interventions: Past, present and future," Internet Intervention, 2018, p. 12.

[32] V. C. Sánchez-Ortiz et al., "A randomized controlled trial of internet-based cognitive-behavioural therapy for bulimia nervosa or related disorders in a student population," Psychological Medicine, 2011, vol. 41, no. 2, pp. 407-417.

[33] S. Helbig and L. Fehm, "Problems with homework in Cbt: Rare exception or rather frequent?" Behavioural and Cognitive Psychotherapy, 2004, vol. 32, no. 3, pp. 291-301.

[34] P. Sedlmeier et al., "The psychological effects of meditation: A meta-analysis," Psychological Bulletin, 2012, vol. 138, no. 6, pp. $1139-1171$.

[35] A. D. Frostadottir and D. Dorjee, "Effects of mindfulness based cognitive therapy (MBCT) and compassion focused therapy (CFT) on symptom change, mindfulness, self-compassion, and rumination in clients with depression, anxiety, and stress," Frontiers in Psychology, 2019, vol. 10, p. 1099

[36] R. M. Niemiec, Mindful Living: Character Strengths Interventions as Pathways for the Five Mindfulness Trainings, 2013

[37] P. L. Alex et al., "Using signature strengths in pursuit of goals: Effects on goal progress, need satisfaction, and well-being, and implications for coaching psychologists," International Coaching Psychology Review, 2010, vol. 5, no. 1, pp. 6-15.

[38] R. Niemiec, T. Rashid, and M. Spinella, "Strong mindfulness: Integrating mindfulness and character strengths," Journal of Mental Health Counseling, 2012, vol. 34, no. 3, pp. 240-253.

[39] A. C. T. Sunawan and Haryono, "School counselors' intention to use technology: The technology acceptance model, TOJET: The Turkish Online Journal of Educational Technology, 2018, vol. 17, no. 2.

[40] L. Hernawati, D. Y. P. Sugiarto, P. Edy, and Awalya, "The effectiveness of cyber counseling service to enhance student performance in statistics," Advances in Social Science, Education and Humanities Research (ASSEHR), 2018, p. 247.

Copyright $\odot 2021$ by the authors. This is an open access article distributed under the Creative Commons Attribution License which permits unrestricted use, distribution, and reproduction in any medium, provided the original work is properly cited (CC BY 4.0).

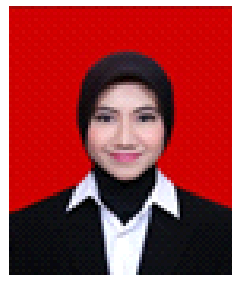

Rohmatus Naini was born at Sidoarjo on January 31, 1993. She graduated in Yogyakarta State University, guidance and counseling undergraduate program. Currently, he is completing a postgraduate program at Universitas Negeri Semarang and work as a volunteer of lay counselor in ActMental. Researcher's experience as a counselor assistant at UNY, and enumerator research collaboration between UNY \& Curtin University. The research focuses of interest are wellness, positive psychology, mindfulness and character strengths.

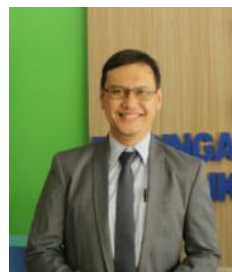

Mulawarman Mulawarman was born in Lahir di Kebumen on December 23, 1977. Currently, he is a lecturer in guidance and counseling, Faculty of Education at Universitas Negeri Semarang, at the undergraduate, master, doctoral and professional programs. He completed his bachelor's and master's degree in Malang State University. He obtained his doctoral degree in philosophy (Ph.D) in 2015 at the School of Psychology, Central China Normal University (CCNU) -China with expertise in counseling psychology or educational psychology. Some of his books include: SFBC (Solution-focused brief counseling) konsep, riset dan prosedur (Jakarta: Prenadamedia group, 2019); psikologi konseling (Jakarta: Prenamedia group, 2019); Konseling Kelompok Pendekatan Realita: Pilihan dan Tanggung Jawab (2020); mind-skills: konsep dan aplikasi dalam praktik konseling (Jakarta: Prenamedia group, 2020); Problematika Pengguanan internet (Jakarta: Prenamedia group, 2020). His research interests in the field of counseling focus on the scope of Educational Counseling, Brief Counseling, Cyber-psychology \& Problematic internet use, Community intervention.

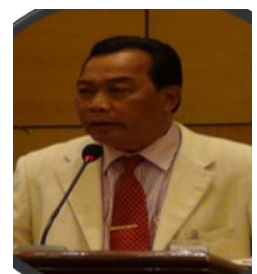

Mungin Eddy Wibowo was born in Banjarnegara on November 20, 1952. He is professor in guidance and counseling departemen, faculty of education, Universitas Negeri Semarang. He currently works as a lecturer in undergraduate guidance and counseling programs, master and doctoral programs, and professional counselor programs. In addition, he also serves as chairman of the UNNES professors' board and has served as chairman of the Indonesian guidance and counseling association. Some of his books include is profesi konseling abad 21 (Semarang: Unnes Press, 2019); Konseling kelompok perkembangan (Semarang: Unnes Press, 2019) etc. His research interests are in the fields of developmental counseling, group counseling, 21st century counseling, professional counselor competence. 